\title{
MULTIDISCIPLINARY MANAGEMENT OF A RARE CASE OF MIXED TOTAL ANOMALOUS PULMONARY VENOUS CONNECTION
}

\author{
Filippo Ghidini ${ }^{1}$, Biagio Castaldi ${ }^{1}$, Massimo Padalino $^{2}$, and Patrizia Dall'Igna ${ }^{3}$ \\ ${ }^{1}$ University of Padua \\ ${ }^{2}$ Pediatric and Congenital Cardiac Surgery \\ ${ }^{3}$ University of Bari
}

January 29, 2021

\begin{abstract}
A rare case of mixed total anomalous pulmonary venous connection (TAPVC) associated to right extra-lobar bronchopulmonary sequestration (BPS) was diagnosed at birth in a full-term newborn. At one month of age, the patient underwent embolization of the BPS, complicated by coil entrapment in the right common iliac artery requiring urgent laparotomy. Few days later, the congenital cardiac repair was accomplished uneventfully. At 12-months follow-up, the patient did not have pulmonary hypertension, but presented a moderate stenosis of the right femoral artery, which was effectively treated with anticoagulation therapy.
\end{abstract}

\section{Hosted file}

TAPVC_final.pdf available at https://authorea.com/users/382843/articles/506270multidisciplinary-management-of-a-rare-case-of-mixed-total-anomalous-pulmonary-venousconnection

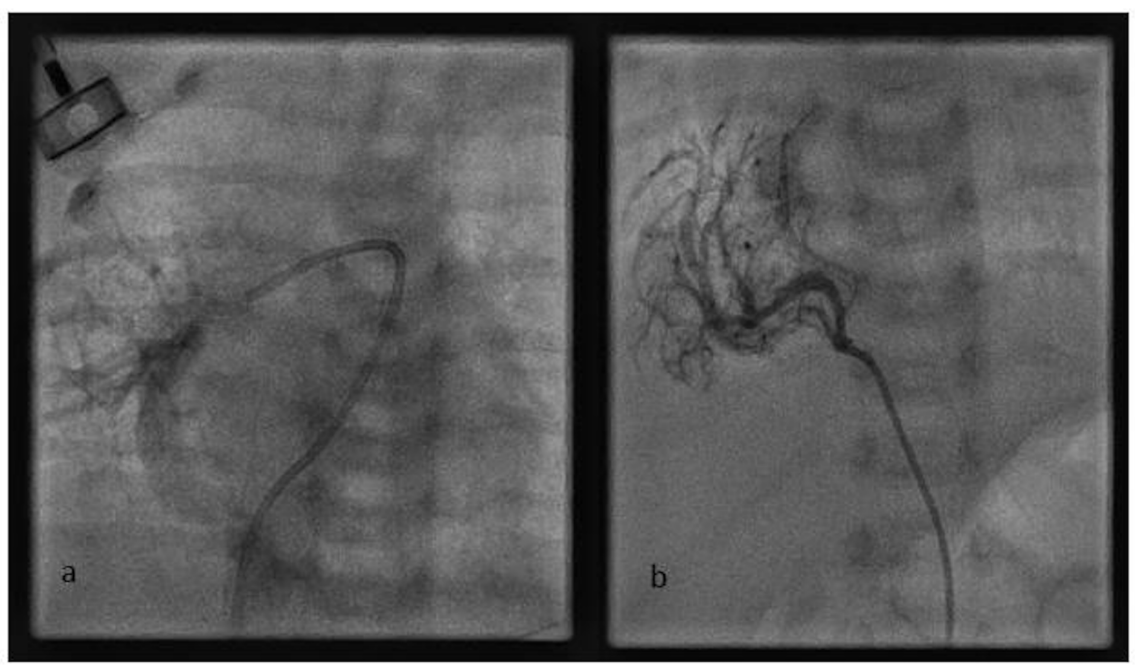




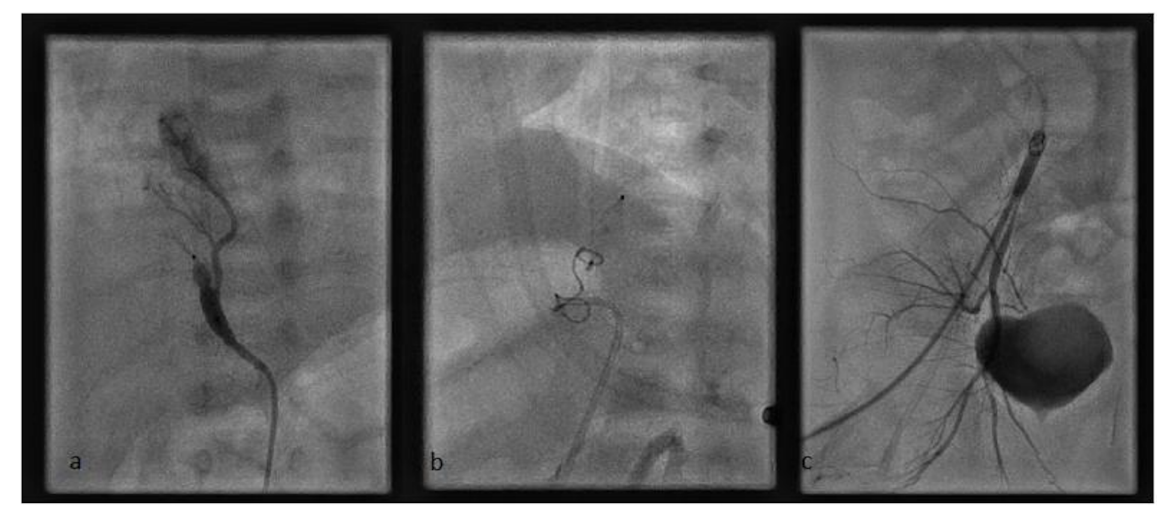

